\title{
Source process of the 2011 off the Pacific coast of Tohoku Earthquake with the combination of teleseismic and strong motion data
}

\author{
Yasuhiro Yoshida ${ }^{1}$, Hiroshi Ueno ${ }^{2}$, Daisuke Muto ${ }^{2}$, and Shigeki Aoki ${ }^{1}$ \\ ${ }^{1}$ Seismology and Volcanology Research Department, Meteorological Research Institute, 1-1 Nagamine, Tsukuba, Ibaraki 305-0052, Japan \\ ${ }^{2}$ Seismological and Volcanological Department, Japan Meteorological Agency, 1-3-4 Otemachi, Chiyoda-ku, Tokyo 100-8122, Japan
}

(Received April 13, 2011; Revised May 12, 2011; Accepted May 13, 2011; Online published September 27, 2011)

\begin{abstract}
We have derived preliminary results for the source process of the March 11, 2011 off the Pacific coast of Tohoku Earthquake (the 2011 Tohoku Earthquake; $M_{\mathrm{w}}=9.0$ ) from two types of seismic waveform data: teleseismic $P$ waves and regional strong motion data. The common features of these two analyses are as follows: (a) The main rupture is located to the east of the initial break point (the shallower side of the hypocenter), and maximum slip amounts were more than $25 \mathrm{~m}$. (b) The size of the main fault was about $450 \mathrm{~km}$ in length and $200 \mathrm{~km}$ in width; the duration of rupture was more than $150 \mathrm{~s}$; and $M_{\mathrm{w}}$ was 9.0 . (c) The initial rupture gradually expanded near the hypocenter $(0-40 \mathrm{~s})$ and subsequently propagated both southwards and northwards.
\end{abstract}

Key words: Source process, teleseismic wave, strong motion, the 2011 off the Pacific coast of Tohoku Earthquake.

\section{Introduction}

A gigantic interplate earthquake occurred on March 11, 2011 at 14:46 (JST) to the northeast of mainland Japan. The hypocenter determined by the Japan Meteorological Agency (JMA) was at $38.10 \mathrm{~N}, 142.86 \mathrm{E}$, depth $23.7 \mathrm{~km}$. A very large tsunami hit the Pacific coastline of the Tohoku and Kanto area with maximum heights greater than $10 \mathrm{~m}$. JMA estimated $M_{\mathrm{w}}$ to be 9.0 from centroid moment tensor (CMT) analysis using long-period global data. It was the greatest earthquake ever recorded by seismometers around Japan. Tens of thousands of fatalities occurred, mainly from the tsunami.

In this region, the Pacific plate is subducting beneath northeastern Japan at the Japan Trench. The convergence rate is about $8 \mathrm{~cm} / \mathrm{yr}$ in the WNW direction (Wei and Seno, 1998). Many $M 7$ class earthquakes have occurred in this region (Yamanaka and Kikuchi, 2004), but few events greater than $M 8$ have occurred in the last several hundred years. The Meiji-Sanriku earthquake of 1896, which triggered an abnormally large tsunami, is one such event. The average slip during this event was 5.9-6.7 $\mathrm{m}$ (Tanioka and Seno, 2001), yet the total slip released by seismic waves was far less than that accumulated from plate coupling over the last several hundred years. This suggests a high coupling rate as pointed out by GPS analysis (Nishimura et al., 2004). The mechanism of releasing the slip deficit in this region is a topic of much research. One candidate for this kind of event is the Jogan earthquake of $\mathrm{AD} 869$, for which $M_{\mathrm{w}}$ has been estimated at more than 8.4 by comparing the distribution of tsunami deposits with numerical tsunami simu-

Copyright (c) The Society of Geomagnetism and Earth, Planetary and Space Sciences (SGEPSS); The Seismological Society of Japan; The Volcanological Society of Japan; The Geodetic Society of Japan; The Japanese Society for Planetary Sciences; TERRAPUB.

doi:10.5047/eps.2011.05.011 lations (Satake et al., 2008; Namegaya et al., 2010), but the size and mechanism of this event are uncertain.

In this study, we have estimated the source process of the 2011 Tohoku Earthquake by using both teleseismic $P$ waves and regional strong motion data. We then considered the relation between the large slip area and interplate coupling in the source region.

\section{Teleseismic Waveform Analysis 2.1 Data and method}

We retrieved broadband data with vertical components of teleseismic $P$ waves from the Data Management Center of the Incorporated Research Institutions for Seismology (IRIS), selecting 41 stations with epicentral distances between $30^{\circ}$ and $100^{\circ}$. The data were integrated to displacement and band-pass filtered between 0.002 and $1.0 \mathrm{~Hz}$. Figure 1 shows locations of the mainshock and aftershocks $(M \geq 5.0)$ from the unified JMA catalog. The initial size of the fault plane was taken to be $510 \mathrm{~km} \times 240 \mathrm{~km}$ from the aftershock distribution, and the rupture was assumed to start at the hypocenter of the mainshock. We divided the fault into subfaults $30 \mathrm{~km} \times 30 \mathrm{~km}$ in size, each with strike and dip angles fixed at $201^{\circ}$ and $9^{\circ}$, respectively, in accordance with the quick Global CMT solution. This mechanism is almost identical to the strike and dip angles of the subducting Pacific plate. The moment rate function for each subfault was expressed by 10 basic triangle functions with 8 $\mathrm{s}$ durations overlapping by $4 \mathrm{~s}$, which can cover a 44 -s rupture duration at each subfault. The spatiotemporal distribution of slip on the fault plane was inverted by the teleseismic body-wave inversion program (Kikuchi and Kanamori, 2003) developed by Kikuchi and Kanamori (1991). The body-wave Green's functions were computed for a simplelayered oceanic model with a $3 \mathrm{~km}$ water depth referred to the Jeffreys-Bullen model. No time adjustments were 
(a)

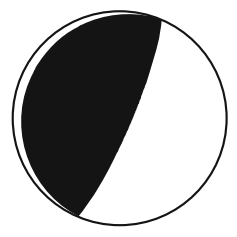

(b) Moment rate function $\left(\times 10^{18} \mathrm{Nm} / \mathrm{s}\right)$
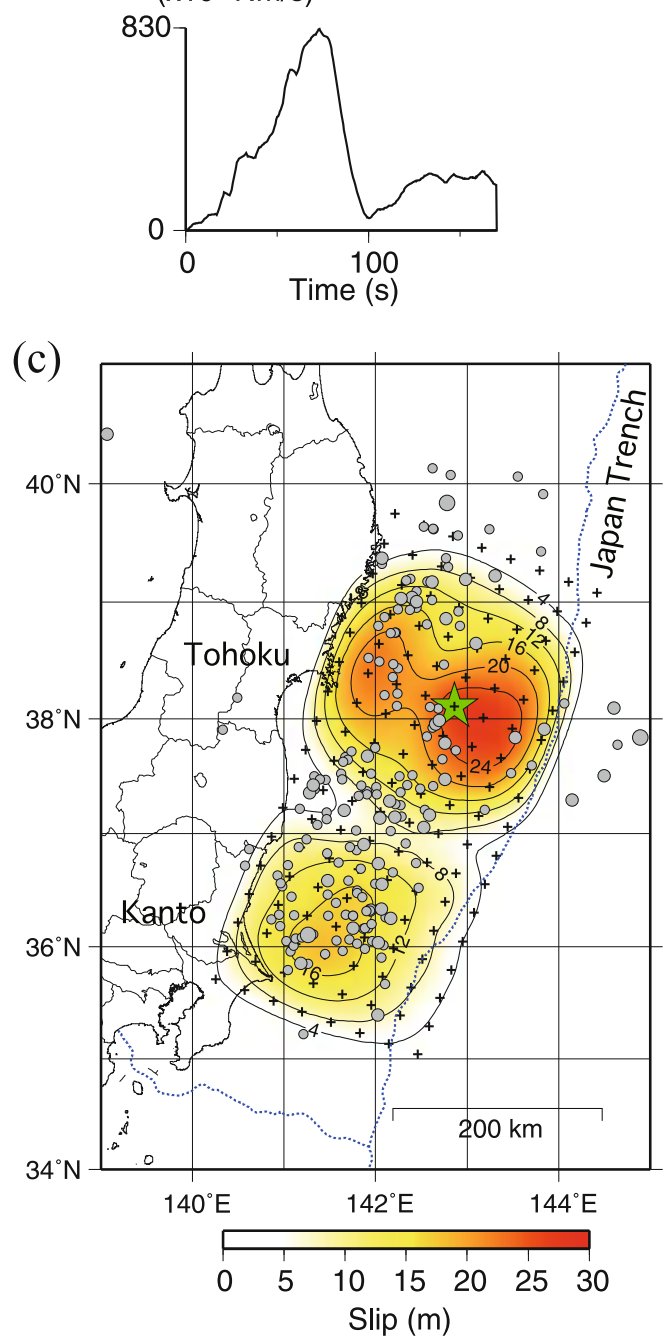

Fig. 1. Finite-source model from inversion of teleseismic waves. (a) Focal mechanism. (b) Moment rate function. (c) Slip distribution on the fault. The large green star represents the epicenter of the mainshock $\left(M_{\mathrm{w}}=9.0\right)$, and gray circles represent aftershocks $(M \geq 5.0)$ within $24 \mathrm{~h}$ of the mainshock. Crosses represent grid points on the fault plane for calculating synthetic waveforms. Contour interval in slip distribution is $4 \mathrm{~m}$.

used for waveform alignments and weights on waveforms were equal. An optimal maximum rupture velocity of 1.8 $\mathrm{km} / \mathrm{s}$, minimizing residuals between observed and calculated waveforms, was selected by trial and error.

\subsection{Inversion results}

The results of our teleseismic waveform inversion are shown in Fig. 1. Figure 2 shows the observed and calculated waveforms and the distribution of stations used in this analysis. The total seismic moment is $4.3 \times 10^{22} \mathrm{~N} \mathrm{~m}$ $\left(M_{\mathrm{w}}=9.0\right)$. There are three major stages of slip (asperities) during the event at about 20-40 s, 40-90 s, and after (a)
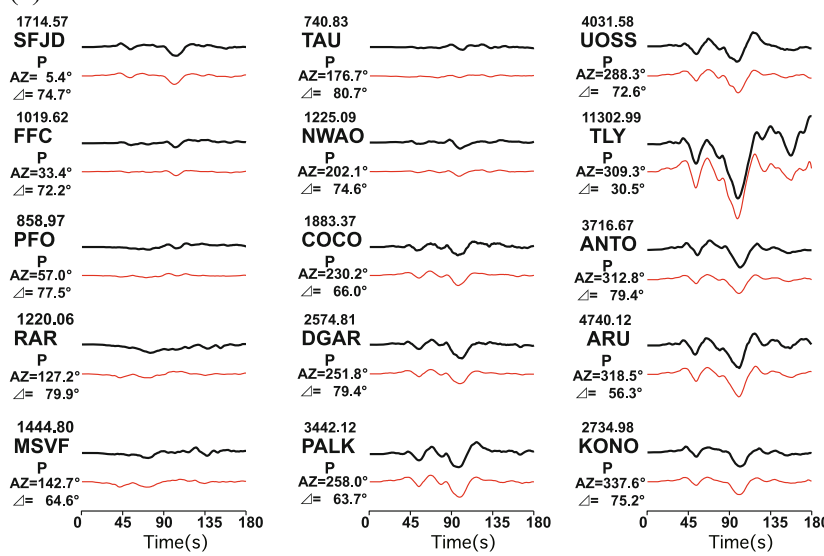

ANTO

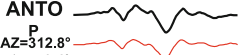

ARU

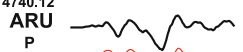

$\mathrm{A}=318.5^{\circ}$
$\Delta=563^{\circ}$

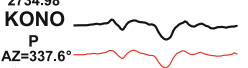

$\mathrm{AZ}=337.6^{\circ}$

$\begin{array}{lllll}0 & 45 & 90 & 135 & 180\end{array}$

(b)

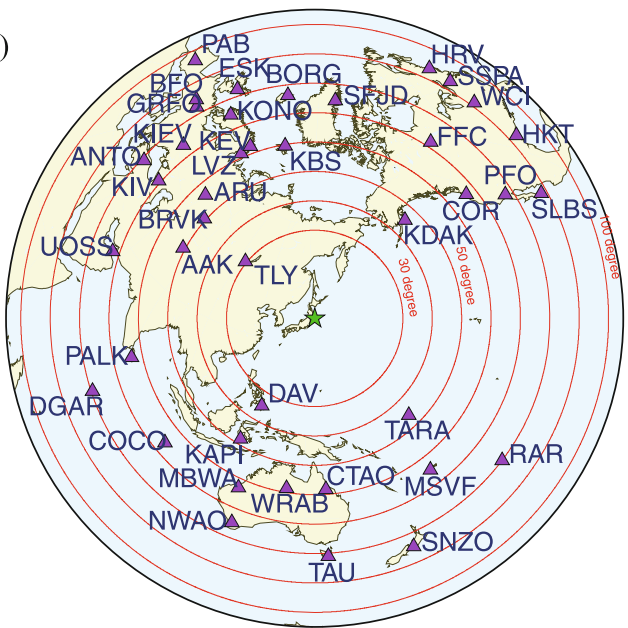

Fig. 2. (a) $P$ wave waveform fits for the teleseismic inversion. Selected stations used in the inversion are displayed, with observed and calculated waveforms shown as black (top) and red (lower) lines, respectively. The number above the station code is the peak-to-peak amplitude of the observed waveform (micro-meter) and the number below the station code is the source-to-station azimuth and epicentral distance. (b) Distribution of stations, with red circles representing epicentral distances between $30^{\circ}$ and $100^{\circ}$ from the mainshock in $10^{\circ}$ increments.

$100 \mathrm{~s}$ following the initiation of rupture (Fig. 1(b)). The rupture duration is more than $150 \mathrm{~s}$, but we cannot discuss the exact duration because of the contamination of $P P$ or $P c P$ phases. The first asperity corresponds to the first peak in the observed data and is located near the hypocenter. The second and largest one, corresponding to the second peak in the observed data, is distributed on the shallower side (east) of the fault plane near the hypocenter. The third one is about 200-300 km SSW of the hypocenter. The maximum slip is about $28 \mathrm{~m}$ if the rigidity is assumed to be $30 \mathrm{GPa}$. The reduction of variance in our inversion is about $75 \%$, and the overall fit between observed and calculated data is good.

\section{Regional Strong Motion Waveform Analysis \\ 3.1 Data and method}

Twenty-three strong motion seismograms from K-NET (Kinoshita, 1998) and KiK-net stations (Aoi et al., 2000), deployed by the National Research Institute for Earth Science and Disaster Prevention (NIED) and from the JMA, were used in this analysis (Fig. 3). We did not use seismic data from JMA stations in the Tohoku district, where the 
(a)

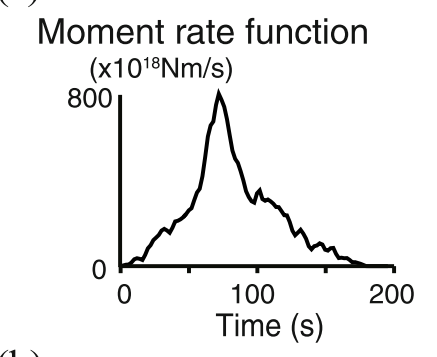

(b)

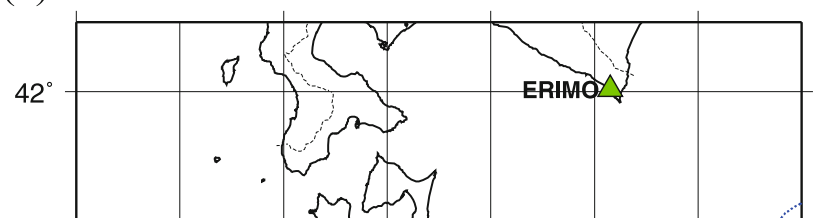

$38^{\circ}$

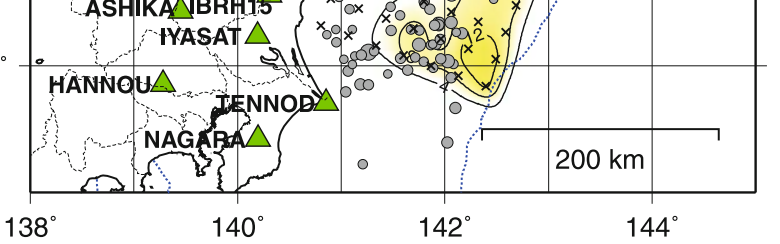

0510152025303540 Slip (m)

Fig. 3. Finite-source model from inversion of strong motion waves. (a) Moment rate function. (b) Slip distribution on the fault. The large green star represents the epicenter of the mainshock $\left(M_{\mathrm{w}}=9.0\right)$, and gray circles represent aftershocks $(M \geq 5.0)$ within $24 \mathrm{~h}$ of the mainshock. Crosses represent grid points on the fault plane for calculating synthetic waveforms. Triangles denote seismic stations used in this analysis. Contour interval in slip distribution is $4 \mathrm{~m}$. The light blue rectangle shows the estimated peak of the highly uplifted area obtained from tsunami arrival times (Hayashi et al., 2011).

telemetric system failed. Acceleration seismograms were integrated to velocity, then the data were band-pass filtered between 0.01 and $0.15 \mathrm{~Hz}$ and decimated to $0.5 \mathrm{~Hz}$. We used $250 \mathrm{~s}$ of data, starting from $10 \mathrm{~s}$ before the $P$ wave arrivals. The strike and dip angles of the fault plane was fixed at the same values used in teleseismic waveform analysis. The fault size was taken to be $475 \mathrm{~km} \times 175 \mathrm{~km}$, and the rupture was assumed to start at the hypocenter of the mainshock. We divided the fault into subfaults $25 \mathrm{~km} \times 25 \mathrm{~km}$ in size.

The Green's function for each subfault was calculated

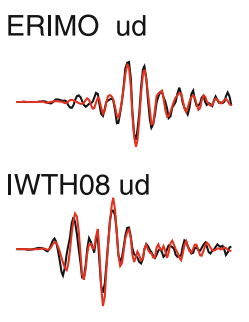

ERIMO ns

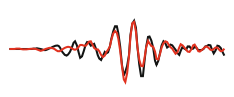

IWTH08 ns

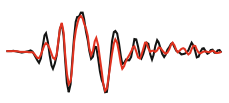

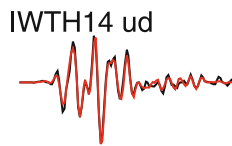

IWTH14 ns

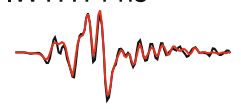

IWT007 ud

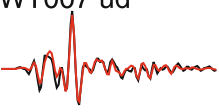

IWT007 ns

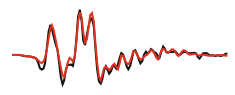

MYGHO4 ud

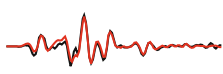

MYGHO4 ns

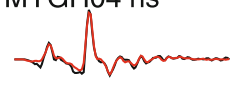

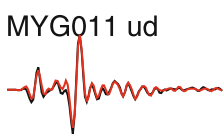

MYG011 ns

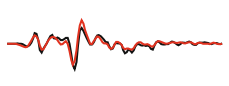

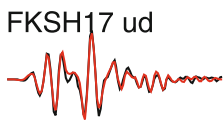

FKSH17 ns

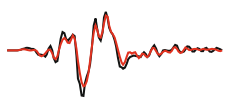

FKSH12 ud

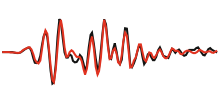

FKSH12 ns

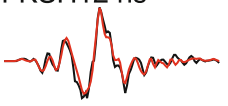

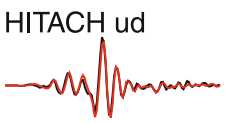

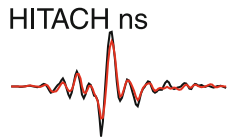

TENNOD ud
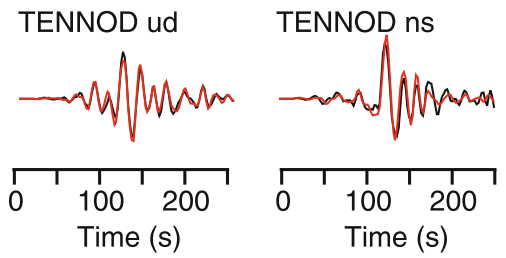

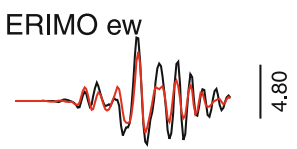

IWTH08 eW

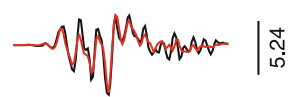

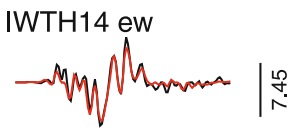

IWT007 ew

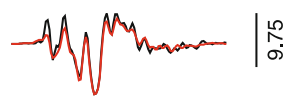

MYGH04 ew

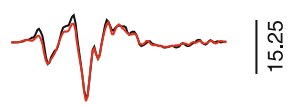

MYG011 ew

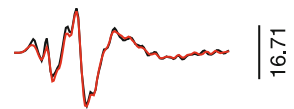

FKSH17 ew

Wy Whand im

FKSH12 ew

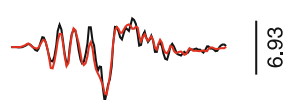

HITACH ew

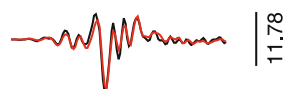

TENNOD ew

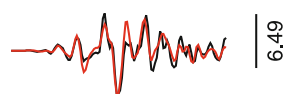

Fig. 4. Comparison of observed (black lines) and calculated (red lines) waveforms for selected stations. The velocity amplitude scale for each station is displayed to the right of the waveforms in $\mathrm{cm} / \mathrm{s}$.

by the discrete wavenumber method (Bouchon, 1981) using reflection-transmission matrices (Kennett and Kerry, 1979). The anelasticity effect was included by the use of complex velocity (Takeo, 1985). A stratified layered structure (Wu et al., 2008) was assumed in calculating the Green's functions. The moment rate function for each subfault was expressed by 20 basic triangle functions with 8 s duration overlapping by $4 \mathrm{~s}$, which can cover an 84-s rupture duration at each subfault. The maximum rupture velocity was set at $2.5 \mathrm{~km} / \mathrm{s}$ to minimize variance. We used the linear multiple time window inversion method with constraints on the smoothness of the spatiotemporal slip distribution (e.g., Ide et al., 1996; Nakayama and Takeo, 1997). The smoothness parameters (hyperparameters) were selected to minimize 


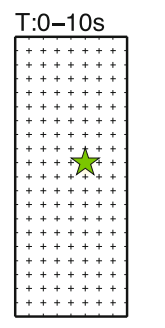

T:60-70s

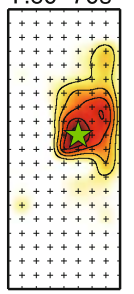

$\mathrm{T}: 120-130 \mathrm{~s}$

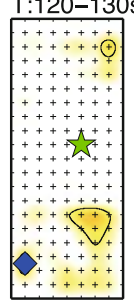

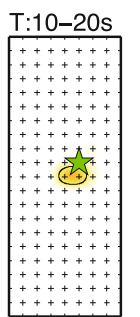

$\mathrm{T}: 70-80 \mathrm{~s}$

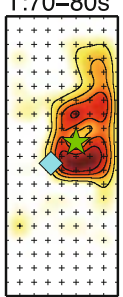

$\mathrm{T}: 130-140 \mathrm{~s}$
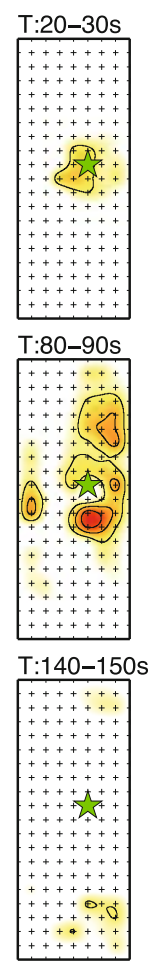

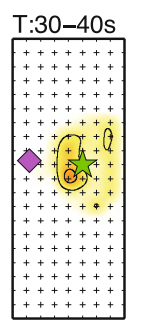

$\mathrm{T}: 90-100 \mathrm{~s}$

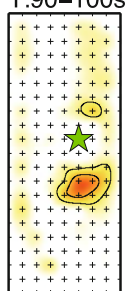

$\mathrm{T}: 150-160 \mathrm{~s}$

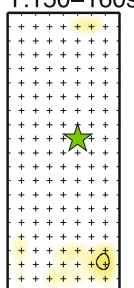

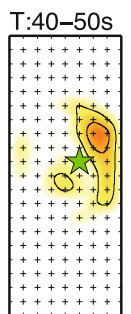
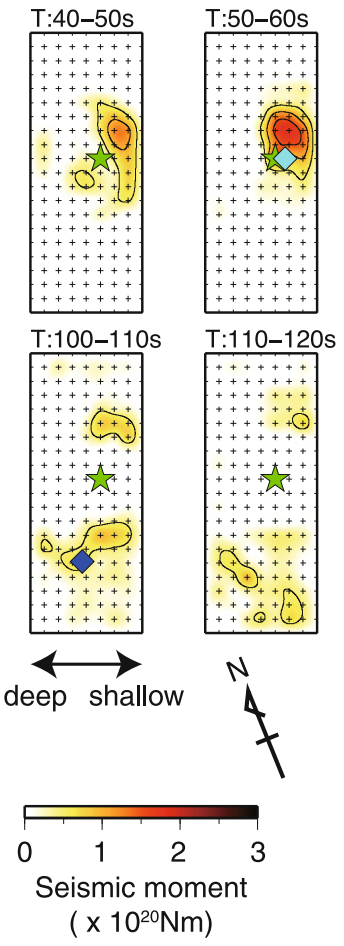

Fig. 5. Snapshots of the rupture propagation at 10-s intervals derived from strong motion inversion. The area of the figures corresponds to the grids in Fig. 3. The seismic moment release during each interval is shown by colors. Contour interval is $0.5 \times 10^{20} \mathrm{~N} \mathrm{~m}$. The star indicates the hypocenter. Diamonds corresponding to strong high-frequency radiation sources during the first, second, and third rupture stages (see Section 4 ) are shown in magenta, light blue, and blue, respectively.

Akaike's Bayesian information criterion (ABIC) (Akaike, 1980; Fukahata et al., 2003). Waveforms were aligned by onset time and weights on waveforms were equal for all stations.

\subsection{Inversion results}

Figure 3 shows the slip distribution obtained from the regional strong motion data analysis. The total seismic moment was $3.4 \times 10^{22} \mathrm{~N} \mathrm{~m}\left(M_{\mathrm{w}}=9.0\right)$, which is slightly smaller than that obtained by the teleseismic waveform inversion but comparable. The slip area extends eastwards from the hypocenter to the shallower part of the fault plane. The maximum slip amount is $38 \mathrm{~m}$. The overall fit between observed and calculated waveforms is quite good (Fig. 4), with a reduction in variance of about $91 \%$.

Snapshots of the distribution of released seismic moment at 10-s intervals are shown in Fig. 5. In the first stage of the rupture $(0-40 \mathrm{~s})$, the rupture expands outwards from the hypocenter, which corresponds to the first peak of the observed data in the Tohoku area (Fig. 4). In the next stage $(40-80 \mathrm{~s})$, the rupture area extends towards the shallow part of the fault plane in both north and south directions. This stage corresponds to the second peak of observed data in Tohoku and causes large slip amounts and may be related to the generation of the large tsunami. The rupture velocity is very slow $(\sim 1 \mathrm{~km} / \mathrm{s})$ during the first and second stages, and the rupture duration is long $(\sim 80 \mathrm{~s})$. In the third stage (after $80 \mathrm{~s}$ ), the rupture extends southwards, reaching the southern end of the fault plane at $160 \mathrm{~s}$. The amplitude peaks in the southern part of the rupture area are due to the superposition of moment release from the second and third stages.

\section{Discussion and Conclusions}

A large slip area near, and offshore of, the hypocentral region with maximum slip exceeding $25 \mathrm{~m}$ is obtained by both teleseismic and regional source process analyses. The shape of the large slip area is similar in both analyses, but the points at the maximum slipped area near the trench differ somewhat (about $50 \mathrm{~km}$ ). This might be due to the location error of these analyses. The maximum slip is larger in the regional analysis because of a spatially finer resolution. This region also coincides with the area of large coseismic slip obtained by GPS analysis (GIJ, 2011) except near the trench, where a small coseismic slip was estimated by GPS. The difference partly reflects the poor resolution of GPS data near the trench. In the tsunami waveform inversion (Fujii and Satake, 2011), the area of large slip also can be seen near the trench just east of the hypocenter. The region where tsunami back-propagation curves of initial crests are concentrated (Hayashi et al., 2011), shown in Fig. 3, is almost coincident with the area of large slip obtained in this study. These results strongly suggest the existence of a strong asperity near the trench. However, the inferred slip distribution in the southern part of the rupture area is not identical in the teleseismic and regional analyses. This suggests that the location error is greater than that in the northern part, but the slip amount we inferred is necessary to explain the strong waveform peaks at stations in the Kanto area (e.g., station HITACH in Fig. 4).

Interplate coupling in northeastern Japan has been investigated by many researchers using the GPS network. Nishimura et al. (2004) found that interplate coupling was strong during 1995-2002 in the epicentral region, where a 
very large slip was estimated by this study. A low ratio of the number of small repeating earthquakes to the total number of earthquakes was observed in the area of large slip (Uchida et al., 2002), which is also suggestive of strong interplate coupling in this region. These observations suggested the potential for the occurrence of earthquakes.

Aoki et al. (2011) carried out a rough estimation of the sources of high-frequency energy using the SourceScanning Algorithm developed by Kao and Shan (2007). The short period (4-8 Hz) RMS velocity envelopes of KNET and KiK-net stations were used. Five high-frequency sources (HFS) were imaged during this event (Fig. 5). The first HFS was in the first rupture stage, the second and third HFSs in the second stage, and the fourth and fifth HFSs in the third stage. The rupture progress of HFSs in a NS direction was almost the same as that estimated by the strong motion data analysis. The HFSs are generally located on the rim of the large slip patch obtained by the strong motion data analysis. This result is similar to that of the 1994 Sanriku-Haruka-Oki earthquake (Nakayama and Takeo, 1997).

In source process analyses with the combination of teleseismic and regional strong motion data, we have found the following features: The main rupture is located to the shallower side of the hypocenter, and maximum slip amounts were more than $25 \mathrm{~m}$. The size of the main fault was about $450 \mathrm{~km}$ in length and $200 \mathrm{~km}$ in width; the duration of rupture was more than $150 \mathrm{~s}$; and $M_{\mathrm{w}}$ was 9.0. The initial rupture gradually expanded near the hypocenter $(0-40 \mathrm{~s})$ and subsequently propagated both southwards and northwards. But there are some differences between the two approaches. Constructing a source process model by joint inversion of teleseismic and regional strong motion data such as Yagi et al. (2004) is an important next step.

Acknowledgments. The authors thank M. Hoshiba, K. Kuge and an anonymous reviewer for helpful comments. Figures were prepared using Generic Mapping Tools (Wessel and Smith, 1995). Teleseismic seismograms were distributed by IRIS DMC. Strong motion seismograms from NIED K-NET, NIED KiK-net and the JMA network were used in this study. We used a teleseismic bodywave inversion program developed by Kikuchi and Kanamori (2003).

\section{References}

Akaike, H., Likelihood and the Bayes procedure, in Bayesian Statics, edited by J. M. Bernardo, M. H. DeGroot, D. V. Lindley, and A. F. M. Smith, University Press, Valencia, Spain, 1980.

Aoi, S., K. Obara, S. Hori, K. Kasahara, and Y. Okada, New strong-motion observation network: Kik-net, Eos Trans. AGU, 329, 2000.

Aoki, S., Y. Yoshida, M. Hoshiba, and A. Katsumata, Imaging of the highfrequency energy radiation sources of the 2011 Off the Pacific Coast of Tohoku Earthquake, JpGU Meeting 2011, MIS036-P38, 2011.

Bouchon, M., A simple method to calculate Green's functions for elastic layered media, Bull. Seismol. Soc. Am., 71, 959-971, 1981.

Fujii, Y. and K. Satake, Tsunami source of the off TohokuPacific Earthquake on March 11, 2011, http://iisee.kenken.go.jp/ staff/fujii/OffTohokuPacific2011/tsunami_inv.html, 2011.
Fukahata, Y., Y. Yagi, and M. Matsu'ura, Waveform inversion for seismic source processes using ABIC with two sorts of prior constraints: comparison between proper and improper formulations, Geophys. Res. Lett., 30(6), 1305, doi:10.1029/2002GL016293, 2003.

Geospatial Information Authority of Japan, The 2011 off the Pacific coast of Tohoku Earthquake: Coseismic slip distribution model (preliminary), http://www.gsi.go.jp/cais/topic110315-index-e.html, 2011.

Hayashi, Y., H. Tsushima, K. Hirata, K. Kimura, and K. Maeda, Tsunami source area of the 2011 off the Pacific coast of Tohoku Earthquake determined from tsunami arrival times at offshore observation stations, Earth Planets Space, 63, this issue, 809-813, 2011.

Ide, S., M. Takeo, and Y. Yoshida, Source process of the 1995 Kobe earthquake: Determination of spatio-temporal slip distribution by Bayesian modeling, Bull. Seismol. Soc. Am., 86, 547-566, 1996.

Kao, H. and S. Shan, Rapid identification of earthquake rupture plane using Source-Scanning Algorithm, Geophys. J. Int., 168, 1011-1020, 2007.

Kennett, L. N. and N. J. Kerry, Seismic waves in a stratified half space, Geophys. J. R. Astron. Soc., 57, 557-583, 1979.

Kikuchi, M. and H. Kanamori, Inversion of complex body waves-III, Bull. Seismol. Soc. Am., 81, 2335-2350, 1991.

Kikuchi, M. and H. Kanamori, Note on teleseismic body-wave inversion program, http://www.eri.u-tokyo.ac.jp/ETAL/KIKUCHI/, 2003.

Kinoshita, S., Kyoshin net (K-NET), Seismol. Res. Lett., 69, 209-332, 1998.

Nakayama, W. and M. Takeo, Slip history of the 1994 Sanriku-haruka-oki, Japan, earthquake deduced from strong-motion data, Bull. Seismol. Soc. Am., 87, 918-931, 1997.

Namegaya, Y., K. Satake, and S. Yamaki, Numerical simulation of the AD 869 Jogan tsunami in Ishinomaki and Sendai plains and Ukedo rivermouth lowland, Ann. Rep. Active Fault Paleoearthq. Res., 10, 71-89, 2010.

Nishimura, T., T. Hirasawa, S. Miyazaki, T. Sagiya, T. Tada, S. Miura, and K. Tanaka, Temporal change of interplate coupling in northeastern Japan during 1995-2002 estimated from continuous GPS observations, Geophys. J. Int., 157, 901-916, 2004.

Satake, K., Y. Namegaya, and S. Yamaki, Numerical simulation of the AD 869 Jogan tsunami in Ishinomaki and Sendai plains, Ann. Rep. Active Fault Paleoearthq. Res., 8, 71-89, 2008.

Takeo, M., Near-field synthetic seismograms taking into account the effect of anelasticity, Meteorol. Geophys., 36, 245-257, 1985.

Tanioka, Y. and T. Seno, Sediment effect on tsunami generation of the 1896 Sanriku tsunami earthquake, Geophys. Res. Lett., 28, 3389-3392, 2001.

Uchida, N., T. Igarashi, T. Matsuzawa, and A. Hasegawa, Spatiotemporal distribution of interplate quasi-static slip in the northeastern Japan subduction zone, estimated from repeating earthquake analyses, Eos Trans. $A G U, \mathbf{8 3}(47)$, Fall Meet. Suppl., Abstract S52B-1109, 2002.

Wei, D. and T. Seno, Determination of the Amurian plate motion, in Mantle Dynamics and Plate Interactions in East Asia, Geodynamics. Series, 27, edited by M. F. J. Flower, S. L. Chung, C. H. Lo, and T. Y. Lee, pp. 337346, AGU, Washington D.C., 1998.

Wessel, P. and W. H. F. Smith, New version of the Generic Mapping Tools released, Eos Trans. AGU, 76, 329, 1995.

Wu, C., K. Koketsu, and H. Miyake, Source processes of the 1978 and 2005 Miyagi-oki, Japan, earthquakes: Repeated rupture of asperities over successive large earthquakes, J. Geophys. Res., 113, B08316, doi:10.1029/2007JB005189, 2008.

Yagi, Y., T. Mikumo, J. Pacheco, and G. Reyes, Source rupture process of the Tecoman, Colima, Mexico Earthquake of 22 January 2003, determined by joint inversion of teleseismic body-wave and near-source data, Bull. Seismol. Soc. Am., 94, 1795-1807, 2004.

Yamanaka, Y. and M. Kikuchi, Asperity map along the subduction zone in northeastern Japan inferred from regional seismic data, J. Geophys. Res., 109, B07307, doi:10.1029/2003JB002683, 2004.

Y. Yoshida (e-mail: yyoshida@mri-jma.go.jp), H. Ueno, D. Muto, and S. Aoki 